\title{
Imbricaciones entre el Homo Sentimentalis, el trabajo enajenado y la naturaleza. Una mirada reflexiva de las relaciones de producción capitalistas
}

Imbrications between Homo Sentimentalis, alienated work and nature. A reflective look at capitalist relations of production

Diana Gómez Calderón

FLACSO sede Ecuador - Ecuador

Quito, Ecuador

gomez_diana@outlook.com

\section{RESUMEN}

La modernidad capitalista ha significado para el mundo la ruptura metabólica entre el ser humano y la naturaleza, llevando así a cabo un proyecto económico devastador para el ambiente, los pueblos originarios y movimientos en tensiones con la acumulación de capital. Bajo esta problemática, se realiza un análisis bibliográfico sobre las relaciones entre el ser humano y la naturaleza, orientado a la ampliación del concepto de la ruptura metabólica al despojo de las emociones y significados sobre la naturaleza. Se explicita una categoría de ser humano y natura parte de un todo metabólico, pero que en la ciencia y en la sociedad se han contemplado como disociados. De esta forma, se presenta que en diferentes etapas del sistema social la modernidad capitalista rompe esta relación para convertir a la naturaleza en un objeto funcional para la acumulación de capitales.

Palabras claves: ecología política; trabajo enajenado; despojo de las emociones; Homo Sentimentalis; naturaleza

\section{ABSTRACT}

Capitalist modernity has meant for the world the metabolic rupture between human beings and nature, thus carrying out an economic project devastating for the environment, the original peoples, and movements in tension with capital accumulation. Under this problem, a bibliographic analysis is made on the relations between human beings and nature, oriented to the expansion of the concept of the metabolic rupture to the stripping of the emotions and meanings about nature. A category of human being and nature is made explicit, part of a metabolic whole, but which in science and society have been considered as dissociated. In this way, it is presented that in different stages of the social system capitalist modernity breaks this relationship to convert nature into a functional object for the accumulation of capital.

Keywords: political ecology; alienated labor; dispossession of emotions; Homo Sentimentalis; nature 


\section{INTRODUCCIÓN}

El siglo XX marca un hito histórico en temas ambientales, el ser humano se percata del impacto que tiene el desarrollo de las formas de vida sociales en la naturaleza, ya para el siglo XXI, se habla de la crisis ambiental que está enfrentando el planeta, esta es una problemática que ha interpelado a los gobiernos alrededor del mundo (Bravo, 2013), para muestra de ello, en 1992 se lleva a cabo la Conferencia de las Naciones Unidas sobre el Medio Ambiente y el Desarrollo en Río de Janeiro, proclamándose así la declaración de Rio que busca proteger la integridad del sistema ambiental. En el 2012 se lleva a cabo otra Cumbre Rio, la cual promueve el “capitalismo verde". En el año 2008, Ecuador fue protagonista en aceptar los derechos de la naturaleza. Actualmente, fondos de diversos organismos internacionales y de los gobiernos a nivel mundial se direccionan en la protección del ambiente (Bravo, 2013).

Ante esto, es importante reflexionar sobre la modernidad capitalista y el proceso devastador que inherentemente tiene sobre la naturaleza. En este sentido, la apropiación de la naturaleza es un fenómeno que surge en la Región Latinoamericana con la colonización y se mantiene en la actualidad (Alimonda, 2011; Ayala et al, 2017; Escobar, 2011 y Machado, 2010). Por tanto, en este artículo se discute sobre la génesis de la ruptura metabólica entre el ser humano y la naturaleza como una forma de entender el valor de uso que esta adquiere en las sociedades capitalistas (Bellamy-Foster, 2014), más allá, de su constitución de derecho como se establece desde las Naciones Unidas. Pues la naturaleza y el ser humano forman parte de un todo orgánico, que ha adquirido un valor en el mercado y de materia prima en función del sistema económico capitalista (Marx, 2001).

Es por ello, que se enmarca como punto de partida el despojo de las emociones sobre la naturaleza, esta "se fetichiza como economía moral del capital" (Machado, 2012, p. 25), que en la región procede de un orden colonial. En este sentido, las emociones son parte de la condición ontológica del ser humano, a través de la historia, en todo proceso sociocultural y en todo tipo de relaciones sociales las personas han generado afectos, autores como Stallybrass (2008), Lauren Berlant y Nattie Golubov (2012) muestran que el ser humano entabla relaciones afectivas no solo con otras personas, sino también con los objetos, con el espacio y con el entorno. A todos ellos los carga de simbolismos, de recuerdos y de emociones de todo tipo. Su despojo, implica en el ser humano una relación material, objetiva y fetichizada con la naturaleza (Machado, 2012).

El capitalista es el dueño de los medios de producción, por tanto, determina los usos e interacciones que deben tener las personas trabajadoras con estos instrumentos (Marx, 2001). De igual forma, con la propiedad privada la naturaleza le pertenece al capitalista, y este determina su uso. Con la industrialización se consolidó la relación de objeto, epistémicamente la naturaleza es entendida como cosa y en la producción es materia prima y mercancía (Machado, 2010 y Lowy, 2014). Retomando a Machado (2010 y 2012) el argumento central de este artículo considera que el capitalismo ha despojado al ser humano de esas emociones, porque la naturaleza es el entorno primario de explotación. En el capitalismo la naturaleza se transforma en objeto y en mercancía, pasa de tener un valor de uso a un valor de cambio. Así, la naturaleza transformada en objeto adquiere un valor transferible en el mercado, tanto por medio del trabajo como por medio de la mercancía.

Se desarrollan tres fundamentos para explicar la ruptura metabólica del ser humano y la naturaleza: 1. desde el modelo económico de la modernidad capitalista y del colonialismo. 2. Desde la fetichización de la naturaleza. 3. Desde la naturaleza como mercancía de explotación para la supervivencia del trabajador enajenado. En los tres aspectos del capitalismo, se vuelve intrínseco el despojo de las relaciones emocionales y afectivas con el entorno natural, pues, este debe convertirse en objeto de explotación para la acumulación de la riqueza. En el momento en que el entorno natural pierde valor para las sociedades y culturas occidentales, carece también, de importancia vital; la naturaleza provee desarrollo al ser humano solo en su explotación y mercantilización.

Se establece como objetivo del artículo debatir conceptualmente el carácter devastador de la modernidad capitalista sobre la naturaleza. Por un lado, se le quita su cualidad de organismo vital para caracterizarla como una cosa. Por otro lado, el ser humano adquiere un valor de supremacía frente a la naturaleza, este 
decide sobre su explotación al mismo tiempo que sobre sus derechos, es decir su valoración tiene un carácter moral. En este sentido, el capitalismo no puede ser "verde", porque este, al igual como se apropia/ adueña y explota los cuerpos subalternizados, lo hace con la naturaleza.

\section{METODOLOGÍA}

Este artículo es de índole teórica, por tanto, se desarrolló con base en la revisión bibliográfica de textos extraídos principalmente de las bases de datos de EBSCO y JSTOR. Se realizó una problematización sobre la ruptura metabólica entre el ser humano y la naturaleza basada en las teorías marxistas, de la ecología política y feminista. Con esto, se amplía el debate del capitalismo devastador de la naturaleza a uno predominantemente ontológico, donde las relaciones con la naturaleza han sido más que sistema y se han configurado en un solo ser y entorno orgánico. Es decir, en el metabolismo, las emociones, simbolismos y significados tomaron protagonismo en las relaciones humanas con la naturaleza.

Se toma como partida el análisis de las conceptualizaciones marxistas sobre el "metabolismo universal de la naturaleza” y la Gran Fractura dada con la industrialización y la expansión del capitalismo. En el presente, se explica esta gran fractura a partir de un despojo inicial, el de las emociones por el entorno. Es decir, la naturaleza pasa de tener una concepción orgánica a tener una de objeto, así, es explotada y "masacrada" en nombre del "progreso" económico global. Dicha relación se explica desde las significaciones que adquieren las emociones y trabajo; emociones y mercancías y emociones y naturaleza en la modernidad capitalista.

\section{DESARROLLO}

\subsection{La modernidad capitalista como modelo destructivo de la naturaleza}

\subsection{1 ¿Qué es la ruptura metabólica?}

De acuerdo con Bellamy-Foster (2014), el uso que le da Marx al concepto de metabolismo es una crítica a la economía y así fundamentar un elemento central, el proceso de trabajo (Bellamy-Foster, 2014, p. 4). Para Marx, el "hombre es un ser corpóreo, que no forma parte de la naturaleza, es externa a él, y esta tiene carácter de cosa" (Schmidt, 2012, p. 72). Desde las ciencias básicas, la naturaleza fue concebida como materia, Foster, señala que esta conceptualización fue base para el desarrollo de la agricultura capitalista en los países occidentales, que, a su vez, se llega a trasladar a América Latina. En este autor, la revolución industrial-química y la sustitución de fertilizantes orgánicos por los sintéticos marcó el inicio de la Gran Fractura con la naturaleza.

Mientras que, el trabajo formó parte de la vida orgánica, incrustado en las relaciones humano-históricas. Sin embargo, "Marx destacó en El Capital que el rompimiento del ciclo de la tierra en la agricultura capitalista industrializada constituía nada menos que una fractura en la relación metabólica entre los seres humanos y la naturaleza" (Bellamy-Foster, 2014, p. 5). Es decir, el trabajo formó parte de la relación metabólica entre el ser humano y la naturaleza, mas no así el trabajo capitalista, pues este más bien significó su ruptura.

Marx "apuntaba más allá de las fuerzas de acumulación y la tecnología, a la estructura cualitativa, del valor de uso de la economía mercantil: la cuestión de las necesidades humanas y su satisfacción" (Bellamy-Foster, 2014, p. 11). Esto toma fuerza con las discusiones sobre la economía del despilfarro y la creación de mercancías inútiles que sirven exclusivamente para la acumulación de capitales. Así, la explotación y destrucción de la naturaleza proveen de las materias primas necesarias para crear las mercancías que enriquecen el capital.

En este sentido, problematizar el despojo de las emociones sobre la naturaleza antes que la Gran Ruptura, plantea un dilema moral y filosófico de la ruptura metabólica, pues para el capitalismo, es conveniente entender a la naturaleza como un objeto fuera del ser humano. Este como ser superior, racional, a su vez, el sistema social por sobre el natural, de esta forma, la lógica de las sociedades capitalistas debe ser utilizar 
todos los recursos universales para producir y desarrollar un sistema social de "ficciones" que proveen las mercancías.

\subsection{Ruptura metabólica en América Latina}

Se toma como principio para este artículo que la ruptura metabólica entre el ser humano y la naturaleza es de origen colonial e imperial, en este apartado se esbozan tres características con las que se introduce el orden económico a la región latinoamericana. El primero, con el despojo de la tierra producto de la colonización. El segundo, la devastación de la naturaleza en función de un sistema económico global. El tercero, el despojo del conocimiento de los pueblos originarios, por un conocimiento racional, moderno y basado en la objetivación de la vida. Estas se dan en paralelo y aún se mantienen en las lógicas de la modernidad capitalista.

Como primer aspecto, la modernidad colonial significó el despojo de la tierra, se despropió a los pueblos originarios del "todo". En el espacio y en el territorio, fue donde poblaciones originarias reprodujeron la vida metabólica, quitarles el territorio les despropió de su relación con la naturaleza, las ontologías y la cultura, el espacio natural y los bienes comunes pasaron a ser propiedad privada. Retomando a Rosa Luxemburgo sobre la acumulación de capital, esta se desarrolla en dos ámbitos: "uno, tiene lugar en los sitios de producción de plusvalía, es un proceso puramente económico entre capitalistas y asalariados. El otro, entre el capital y las formas de producción no capitalistas, como lo es la política colonial" (s.f. citado en Harvey, 2004, p. 112), la acumulación de capital está situada en dos vertientes, una de relaciones de producción ubicada en un espacio concreto, mientras que otra, en un ámbito político económico, con mayor dificultad de descifrar. Ambos aspectos, de acuerdo con Hervey (2004), deben comprenderse conjuntamente.

En cuanto a Marx, Hervey (2004) describe que la acumulación de capital se da en la desposesión originaria, vinculada con "mercantilización y privatización de la tierra y la expulsión forzosa de las poblaciones campesinas" (2004, p. 13). Posterior a este proceso, se da la desposesión que es producto de la mercantilización de la fuerza de trabajo. En este proceso complejo, Harvey señala que la desposesión originaria no puede analizarse fuera de la producción capitalista y de prácticas depredadoras que están a lo largo de la geografía histórica de acumulación de capital (2004, p. 112).

Acá, el postulado central en Harvey es que "la actual etapa de expansión del capital puede ser caracterizada como de "acumulación por desposesión", proceso que ha producido nuevos giros y desplazamientos, colocando en el centro de disputa la cuestión acerca del territorio y el medio ambiente" (2004, citado en Svampa, 2008, p. 5). En este sentido, para Svampa (2008, p. 5) estas disputas terminan apropiándose de la cultura, las técnicas tradicionales y los conocimientos ancestrales de los pueblos originarios al mismo tiempo que destapa las resistencias y los procesos de pugna por la naturaleza y el territorio.

Segundo, los modos de explotación y destrucción de la naturaleza que toman partida con la modernidad capitalista, introducida a nuestra región posterior a la colonización de América Latina "en esta perspectiva, el discurso de la Modernidad inaugura sobre la entidad naturaleza un estatuto fundacional respecto del orden moderno/colonial" (Machado, 2010, p. 35). Este contexto, definitivamente marcó un punto de quiebre en la historia, organización y cultura. El capitalismo, ha significado un proceso económico devastador del espacio, del ambiente y de los y las seres. Estos han sido espacios en lugar de territorios de conquista, tanto cuerpos como territorios (Machado, 2010, p. 36). El despojo, la violencia y las muertes han estado presentes en América Latina desde la colonización en nombre del progreso occidental. Así, el capitalismo dista de un modelo metabólico, más bien, se introduce uno imperialista y extractivista, que destruye tanto la naturaleza, como las culturas y movimientos en resistencias; el capitalismo no es de otro modo más que salvaje.

La hegemonía, la supremacía eurocéntrica y las lógicas de acumulación de capital, son aspectos que se esconden bajo un discurso desarrollista y modernizatorio de La América Latina, "se ha saqueado el continente con la promesa de acabar con las carencias y construir un mundo más equitativo" (Santos, 2014, citado en Ayala et al, 2018, p. 58). La perspectiva "transmoderna" que surge con el programa Modernidad/ Colonialismo, se posiciona epistémica y críticamente ante la modernidad, estableciendo un giro hacia 
las relaciones entre la sociedad y la naturaleza (Alimonda, 2011, p. 27). Desde los enfoques de la ecología política "no existe modernidad sin colonialidad, ni capitalismo sin extractivismo" (Parra-Romero, citado en Ayala, et al, 2018, p. 60). De esta manera, el capitalismo se expande por los procesos de explotación y despojo de los seres humanos y la naturaleza, con la finalidad de extraer el máximo beneficio económico (Ayala et al, 2018).

\begin{abstract}
El proyecto moderno implicó siempre el ejercicio de un biopoder sobre la naturaleza, entendido como poder sobre los espacios físicogeográficos, los suelos y los subsuelos, los recursos naturales, flora y fauna, el aprovechamiento de las condiciones climáticas, pero también poder sobre los cuerpos humanos subalternizados por la dominación. La biopolítica de los discursos moderno/coloniales no produce solamente subjetividades y territorialidades, produce también "naturalezas", es decir, pone en evidencia la colonialidad de las naturalezas (Alimonda, 2011, p. 52).
\end{abstract}

De acuerdo con Escobar, "el capitalismo ha sido el gran transformador de los lugares en todo el mundo (...) estamos destruyendo nuestro medio ambiente biofísico a una velocidad pasmosa, pareciera como si la modernidad capitalista hubiera declarado guerra a cada ecosistema del planeta" (2011, p. 68). Los modernos ven como extraños los rituales que otras culturas configuran en una forma de ecología cultural, basada en la sostenibilidad entre naturaleza y ser humano. Esta visión de mundo se concibe como atrasada desde el lente moderno (Escobar, 2011), por tanto, desde la política del desarrollo, se entrometen en los territorios para explotarlos bajo la lógica de la modernidad capitalista, esto sucede con formas similares a como ocurrió en la colonización.

Por último, el despojo del conocimiento. Las culturas que no fueron permeadas por el capitalismo, o aquellas previas a este, han presentado otras ontologías entre la cultura y la naturaleza (Descola, 2012 y Howel, 2001). Un aspecto central es reconocer que la racionalidad occidental fue fundante de esta separación dual del mundo. Las visiones totalizantes (fuera de las coloniales y capitalistas) permiten tener una relación no jerárquica ni disociativa entre los seres humanos y los seres no humanos. Estos fueron conocimientos centrales en las culturas originarias. La lectura sobre lo "primitivo" de estas poblaciones precisamente fue por la prioridad del equilibrio con el ambiente natural, en lugar de un sistema artificial como es el económico. Adicionalmente, las lecturas sobre la vida estuvieron trazadas por lo espiritual, sensitivo y mitológico, aspectos, que la racionalidad occidental rechazaba desde la ilustración.

La ilustración nace como una forma de liberar al "hombre" del miedo y así dominar la naturaleza, "en el proceso de ilustración el conocimiento se torna en poder y la naturaleza queda reducida a "pura materia o sustrato de dominio", no soporta lo diferente ni lo desconocido. Y ello marca el curso de la desmitologización, de la ilustración, que termina reduciendo todo a la pura inmanencia" (Horkheimer y Adorno, 1998, p. 12). Este proceso permeó a toda Europa, por tanto, a sus territorios de conquista. El espíritu y los sentidos fueron anulados, así los conocimientos que no fueran "objetivos", los significados y conocimientos en América Latina eran contrarios al sistema mundo hegemónico que se empezaba a configurar posterior a la colonización. De esta forma, la modernidad capitalista debía colonizar las configuraciones simbólicas del mundo, pues debía asegurar la acumulación de capital en todas sus formas. "Este proceso, que quiso ser un proceso liberador, estuvo viciado desde el principio y se ha desarrollado históricamente como un proceso de alienación, de cosificación" (Horkeimer y Adorno, 1998, p. 12), al menos para los mundos distintos a occidente.

La modernidad colonial se ha impuesto con su modelo extractivista y de mercantilización de la naturaleza. Aunque en nuestros territorios, antes de la colonización, los pueblos originarios habían establecido formas de vida equilibradas entre la cultura y la naturaleza. El genocidio y la subalternización de las poblaciones originarias significaron la pérdida de sus conocimientos y de sus formas tradicionales de interactuar con el ambiente natural. Al mismo tiempo que hubo una reorganización selectiva de conocimientos a partir de las nuevas relaciones de poder (Alimonda, 2011, p. 49). 
La mitología permite cargar de significaciones y códigos simbólicos a estas relaciones asociativas (Descola, 2012 y Howel, 2001). En el marco de la ilustración, aspectos como la ancestralidad, los totemismos y los elementos míticos que configuraron las cosmovisiones sobre la vida en las culturas no capitalistas, fueron desvalorizadas y confinadas al mundo de lo "ficticio", la racionalidad despropió a las culturas de sus conocimientos. En estas, no existe una supremacía del ser humano con la naturaleza, como sí se desarrolló en las culturas occidentales. Incluso, en visiones antropocéntricas, se ha concebido al ser humano como una especie de divinidad o deidad terrenal, pues es quien debe "cuidar" a la naturaleza, atribuyéndose así una superioridad moral y valorativa del ser humano. A fin de cuentas, este decide cuáles seres naturales son "sujetos", no en función de una relación metabólica, sino de supremacía y control para la estabilidad del sistema.

\subsection{El trabajo enajenado y la ruptura con la naturaleza en Marx}

Para Marx, la lógica de acumulación de capital se da en primera instancia por la desposesión de la tierra, aunque, la mercantilización de la fuerza de trabajo y la enajenación son aspectos centrales en la ruptura metabólica. El trabajador asalariado y el siervo han sido los delegados/forzados en el capitalismo para manipular, con sus manos y herramientas la naturaleza. El apartado anterior mostró que la modernidad capitalista despropió a las poblaciones originarias de su relación metabólica con la naturaleza, desde la tierra hasta el conocimiento. Este apartado, se refiere al trabajador que debe convertirse en explotador de la naturaleza, por su supervivencia misma. Este aspecto se explica desde el trabajo enajenado, porque está dentro del capitalismo y el modo en el que operan las relaciones de producción.

Se problematiza el trabajo enajenado en Marx, pues, en este concepto se inscribe la objetivación de la vida genérica. El capitalismo transformó, para siempre, las relaciones sociales y culturales. De acuerdo con Marx (2001), el mundo humano se desvaloriza por el mundo de las cosas, en el mundo capitalista el trabajador se convierte en mercancía, a la vez que es productor de mercancías y se produce a sí mismo como mercancía. De este modo, el trabajo se fija de acuerdo con las cosas que produce para el capitalismo, ajenas a él y en un modo de objetivación de su trabajo (Marx, 2001).

Se recuerda que, para Marx fue central explicar el capitalismo partiendo de la relación entre el ser humano con la naturaleza, el trabajo y la producción. Ya que es en el trabajo enajenado que se da la esencia de la propiedad privada (Marx, 2001, p. 68), por varios aspectos: 1) el "hombre" se relaciona con el producto de su trabajo como un objeto extraño; 2) el trabajo existe fuera del trabajador y 3) la objetivación de la vida genérica, de tal manera que el trabajo se convierte en un simple medio (Marx, 2001, pp. 126-130).

\footnotetext{
Mediante el trabajo enajenado crea el trabajador la relación de este trabajo con un hombre que está fuera del trabajo y le es extraño. La relación del trabajador con el trabajo engendra la relación de este con el del capitalista. La propiedad privada es el producto, el resultado, la consecuencia necesaria del trabajo enajenado, de la relación externa del trabajador con la naturaleza y consigo mismo (Marx, 2001, p. 133).
}

En este sistema el trabajo se presenta como un valor de uso, es decir, la fuerza de trabajo del obrero es vendida al capitalista para producir un artículo o bien, que tendrá un valor de cambio en el mercado, es decir, una mercancía. En el capitalismo ese valor de cambio siempre será mayor al valor de uso, por tanto, genera un plusvalor. Así, la ganancia y la acumulación, el capitalista la adquiere con la diferencia del valor de uso y del valor de cambio que no se le paga al obrero, a esto, Marx le llama plusvalía.

Esta relación es aún más compleja, ya que el capitalista es el dueño de los medios de producción y al comprar la fuerza del trabajo del obrero, este queda en una relación de subordinación. En esa relación de subordinación "el obrero queda bajo el control del capitalista, en tanto que controla que produzca de la debida manera y que los medios de producción sean debidamente utilizados" (Marx, 2014, p. 224), esto para maximizar las ganancias del capitalista. A su vez, "el producto es propiedad del capitalista, no 
del obrero" (Marx, 2014, p. 224). De esta forma, al capitalista le pertenecen los medios de producción, el proceso de trabajo (lo ha comprado por medio del salario) y los productos. A esta relación Marx le va a llamar explotación laboral. Así, la sociedad capitalista genera dos clases sociales antagónicas entre sí y determinadas por las relaciones de producción: la clase trabajadora y la clase burguesa.

Así como el comerciante europeo fetichizó los objetos valiosos (Stallybrass, 2008), así como el hombre dominó a la mujer y la desposeyó de sí misma y de su cuerpo, el primer despojo, de acuerdo con Federici (2010), el capitalista también desposeyó al trabajador de su relación con la naturaleza para generar capital a partir de la explotación de los recursos. De esta forma, se considera que el segundo despojo que se da en las dinámicas capitalistas es la relación afectiva del ser humano con la naturaleza, elemento intrínsecamente relacionado con la enajenación del trabajo.

El extrañamiento resultado de la objetivación del trabajo es lo que Marx comprende como la pérdida del objeto producido, pero, para producir el objeto necesita a la naturaleza, en su sentido amplio, "el trabajador no puede crear nada sin la naturaleza, sin el mundo exterior sensible. Esta es la materia en que su trabajo se realiza, en la que y con que produce" (Marx, 2001, p. 57). En esta lógica, según Marx (2001), el trabajador se convierte en siervo de su objeto, del producto final que participa en los mercados de transacciones. Pero, la naturaleza, al ser necesaria para la producción, pierde su cualidad vital y adquiere la de mercancía. De este modo, el trabajador termina explotando la naturaleza en su necesidad de satisfacer la vida material.

Así como su cuerpo se convierte en mercancía, lo hace la naturaleza, ya que esta es "el cuerpo inorgánico del hombre", (Marx, 2001, p. 61), pero adquiere un valor inferior a la del cuerpo del hombre, es objeto. Los subordinados deben despojarse de su relación afectiva con el entorno natural para poder participar de la cadena productiva del capitalismo. Así que, en la relación esencial del trabajador con la producción existe la enajenación, pero también el despojo de las emociones y afectos en toda la actividad productiva. Porque antes del capitalismo o en culturas no capitalistas, dicha relación afectiva y metabólica coexiste y organiza sus mundos.

\footnotetext{
El trabajo, la actividad vital, la vida productiva misma, aparece ante el hombre sólo como un medio para la satisfacción de una necesidad, de la necesidad de mantener la existencia física. La vida productiva es, sin embargo, la vida genérica. Es la vida que crea vida. La vida misma aparece sólo como medio de vida. El trabajo enajenado invierte la relación, de manera que el hombre, precisamente por ser un ser consciente hace de su actividad vital, de su esencia, un simple medio para su existencia (Marx, 2001, p. 62).
}

Con la propiedad privada, el subordinado depende de las clases dominantes para su supervivencia. Así, "el obrero ha de luchar no solo por su subsistencia física, sino también por lograr trabajo, es decir, por la posibilidad, por los medios, de poder realizar su actividad" (Marx, 2001, p. 6). De esta manera el capitalista explota al trabajador, pero, además, por su condición precaria, también lo expropia de su relación afectiva con la naturaleza porque el trabajador debe generar mercancía, debe generar ganancias, esa es la forma de garantizar su trabajo.

Cuando el trabajador es sometido a relaciones de siervo/asalariado es paulatinamente despropiado de su relación afectiva con la naturaleza y el trabajo pasa a dinámicas que favorecen la acumulación de capital. Esta es una ruptura propia de las características racionales y utilitarias de la modernidad. Inicialmente para el terrateniente y posteriormente para el burgués, ya que el objetivar la naturaleza le permite explotarla y acumular capital a partir de esta nueva relación. Esto se consolida con las dinámicas de la agroindustria.

\subsection{La ruptura entre el Homo Sentimentalis y la naturaleza}

En la relación entre capitalismo, ser humano y naturaleza, es necesario establecer el despojo de las emociones sobre la naturaleza. Este proceso se da en paralelo al despojo de la tierra y del conocimiento. Si estos dos aspectos desaparecen de la vida humana del trabajador/siervo, desaparecen las relaciones me- 
tabólicas y afectivas con el entorno. El subordinado trabaja para el capitalista en propiedad privada, con métodos y herramientas que no le pertenecen, ya que, en última instancia, su deber es ser eficiente en la actividad productiva. Es por esto que la modernidad capitalista, en su lógica objetiva, racional y económica de la sociedad, convierte a la naturaleza en un objeto. Primero, es materia prima, segundo, con ella se crean objetos artificiales y, tercero, en su estado mercantil es un objeto natural.

La emoción puede llevarnos a cuidar del entorno natural, a establecer dinámicas socioeconómicas de equilibrio con la naturaleza y definitivamente a no explotarla, "La emoción no es acción per se, sino que es la energía que nos impulsa a un acto" (Illouz, 2007, p. 15). Entonces el Homo Sentimentalis, va más allá de los afectos entre seres humanos, a su vez, la relación con la naturaleza es más que en términos de producción o de equilibrio ecológico. Son también los sentimientos que le atribuyen a la naturaleza y que establecen las relaciones socioculturales con ella. "Sin duda la emoción es un elemento psicológico, pero es en mayor medida un elemento cultural y social" (Illouz, 2007, p. 16).

En este sentido, cuando se problematiza sobre las relaciones de producción que se dan en la modernidad, enseguida se piensa en el Homo Economicus y en el Homo Faber, pero pocas veces se trae a colación el Homo Sentimentalis a los análisis de economía y sociedad, La sociología abandonó de sus análisis sobre la modernidad al Homo Sentimentalis, así han sido escasos los estudios relacionales entre afectos y capitalismo (Illouz, 2007, p. 11). Las emociones son una categoría analítica poco utilizada en los estudios sobre el capital. Desde la sociología, Durkheim (1997) establecía que los hechos sociales hay que estudiarlos como cosas, es decir, se objetiva el proceso de la investigación, se separa la subjetividad y las emociones para entender el mundo. De manera similar, Weber (2002) Ilama a las acciones no racionales aquellas que están orientadas por la emoción, deja entender que el fin último de la humanidad es incorporar los procesos racionales en lo político-económico y en el sentido de la acción. De esta manera, con la ilustración, las emociones al igual que el mito, son aspectos subvalorados, en última instancia no contribuyen a la idea de racionalidad, objetividad y ciencia con la que se funda el sistema moderno capitalista.

De esta misma forma, resulta conveniente para el capitalismo, el fetichismo de la naturaleza. El Homo Sentimentalis se fetichiza en la relación entre ser humano y naturaleza. El capitalista despoja al subordinado de sus afectos sobre el entorno natural para así explotar la naturaleza y la tierra. "La modernidad y el capitalismo eran alienantes en el sentido de que creaban un tipo de entumecimiento emocional que separaba a las personas entre sí, de su comunidad y de su yo profundo" (Illouz, 2007, p. 12) y en primera instancia de la naturaleza. Entonces, la manera en que el ser humano se relaciona con los objetos "naturales" y artificiales está determinada por el ámbito sociocultural, pero también se construye esa relación a partir de los simbolismos, subjetividades y afectos que le atribuimos individual y colectivamente a las cosas.

\subsubsection{La subvaloración de las emociones}

En las sociedades y culturas no capitalistas las emociones y los afectos que tienen las personas con la naturaleza son centrales en la organización de la vida. El trabajo no se da en términos de producción capitalista ni de plusvalor, sino, en términos de metabolismo. Y no es para nada que las sociedades modernas se hayan desligado por completo de la relación emocional con la naturaleza, sino que hay un alejamiento con ella, cada vez menos, la naturaleza es parte del paisaje y del entorno cultural. Pues "la producción fundada en el capital crea por un lado la industria universal; por otro lado, un sistema de explotación general de la apropiación de la naturaleza y del hombre" (Lowy, 2013 p. 3). Con la industrialización la naturaleza adquiere un valor de uso, aunque también puede llegar a ser un valor de cambio. De esta forma, la ruptura metabólica ocurre en la modernidad capitalista, en tanto se explotan los recursos naturales para la producción o bien, se extrae de su entorno para convertirse en mercancía (Bellamy-Foster, 2014).

Para Howell (2001) es importante enunciar, como prueba de igualdad en las especies en las culturas no capitalistas, que todos los personajes humanos o no humanos tienen la cualidad de alma, un debate central que dividió al mundo occidental en términos de especie y de raza. Por ello, las formas sociales y culturales se ven explícitamente orientadas por esta relación con la naturaleza y el entorno. Ingold (2011) establece que hay una división esencialista entre la cultura y la naturaleza. Con el racionalismo cartesiano, se divide el pensamiento de los sentimientos. "Se consideraba que las propiedades de esas dualidades no eran equi- 
valentes: los humanos son superiores a los animales, la mente es superior al cuerpo y, del mismo modo, el pensamiento es superior al sentimiento" (Skultan, 1997, citado en Howell, 2001, p. 149).

Howel (2001) y Descola (2012), defienden el argumento de que las formas de representar a la naturaleza responden a significados sobre la humanidad, aunque, no distinguen al ser humano del entorno, ni entre sentimiento/pensamiento, ni cultura/naturaleza. Así, la dicotomía es propia de la occidentalidad. En este sentido, sí hay una diversidad de especies, pero no están jerarquizadas, sino que cada una de ellas tiene sus "particulares códigos sociales", pues, el ordenamiento está regido por la identificación y no por una clasificación de la diferencia (Howel, 1949, p. 157).

Así, antes de cualquier sistema social, el ser humano ya presentaba emociones y afectos por su entorno, el Homo no se ha relacionado de la misma forma entre seres humanos y su entorno natural. Sin embargo, desde el discurso hegemónico de la racionalidad, las emociones por el entorno se subvaloran y feminizan. Se incrustan modalidades racionales de organización, dejando lo irracional a los espacios privados, es decir, lo emocional pasa al plano de lo familiar y del amor romántico. En el capitalismo, el trabajo público no está impregnado de afectos, todo lo contrario, a la naturaleza se le expropia de su carácter vivo y al trabajador de los afectos que pueda tener con el entorno natural. Los afectos se trasladan a la esfera privada y posteriormente al consumo de la mercancía provistas de valor de cambio.

De este modo, la subvaloración de las emociones es un dilema de la modernidad capitalista, pero también del patriarcado. Desde occidente, lo emocional fue atribuido exclusivamente a las mujeres, por ello, se les privó de la participación en la producción capitalista y la esfera pública en general. La relación de las mujeres con el cuidado de las personas, supuso un cuidado por el entorno natural, así "el trabajo reciente en ecología política feminista ha explorado de qué manera una ética feminista del cuidado puede reimaginar una alternativa poscapitalista a las formas neoliberales de desarrollo basado en la extracción y el consumo de los recursos naturales" (Elmhirst y Gonzákz, 2017, p. 55). Con la colonización, las mujeres mantuvieron relaciones metabólicas con la naturaleza para el cuidado de otros seres, por medio de la medicina natural/ ancestral, la alimentación, el cuidado de plantas y animales. Dentro del ecofeminismo se destaca la explotación de la mujer y de la naturaleza a través del trabajo reproductivo (Svampa, 2015, p. 130). De esta forma, las relaciones emocionales y metabólicas con la naturaleza se enmarcan en el anticapitalismo y el antipatriarcado, necesariamente.

\subsection{La naturaleza transformada en objetos: objeto natural y objeto artificial}

Cuando son mercancía, tanto los objetos como la naturaleza adquieren un alto valor simbólico y se le carga de emociones, pero cuando son materia prima se les despoja de los significados y afectos que las personas le han cargado. Es decir, una planta no tiene el mismo significado cuando hay que arrancarla de la tierra para producir que cuando es comprada en el jardín botánico para llevarla a la casa. Cuando la industria se instala en la montaña para destruirla o se privatizan los "bienes comunes" como la tierra y el agua. La justificación inmediata es el desarrollo y las fuentes de trabajo, y ahí le quitamos a la naturaleza su esencia vital.

\footnotetext{
Se eleva a un nivel social tal que todas las sociedades anteriores aparecen como desarrollos meramente locales de la humanidad y como una idolatría de la naturaleza. de hecho, la naturaleza se vuelve un puro objeto para el hombre, una cosa util. no se le reconoce ya como una fuerza. la inteligencia teórica de la ley natural tiene todos los aspectos de la artimaña que intenta someter la naturaleza a las necesidades humanas, sea como objeto de consumo, sea como medio de producción (Marx 1967, citado en Lowy, 2003, p. 3)
}

Para Stallybrass (2008) los objetos fabricados no son solo cosas que "visten", facilitan el trabajo cotidiano o satisfacen los deseos. El objeto no es consumido solo por su uso sino por su fetichización. "En El Capital, el saco de Marx aparece sólo para desaparecer otra vez, porque la naturaleza del capitalismo es producir un saco no como una particularidad material sino como un valor "suprasensible" (Marx, 1976, citado en 
Stallybrass 2008, p. 2). Sin embargo, el valor suprasensible del objeto fabricado y del objeto natural adquieren valoraciones distintas en el capitalismo. Al primero se le carga de significados y de simbolismos por ser mercancía en el mercado y al segundo se le despoja de todo ello por ser mercancía en la actividad productiva, pero ambos, al fin de cuentas son objeto de valor.

No es con la modernidad que se genera el deseo y los afectos por los objetos, sino que, como lo retoma Stallybrass (2008), el materialismo antecede al capitalismo y a la modernidad, pero, desde el discurso hegemónico de la racionalidad, los afectos han sido utilizados para la dominación y el control.

Como Marcel Mauss escribió en Ensayo sobre el don, su libro fundacional sobre el intercambio precapitalista, los objetos en tales intercambios pueden "personificar seres que hablan y toman parte en el contrato. Ellos declaran su deseo de ser cedidos". Cosas-como-dones no son "cosas indiferentes"; ellos tienen "un nombre, una personalidad, un pasado" (Mauss, 1967, citado en Satallybrass, 2008, p. 3).

Lo planteado por Stallybrass (2008) permite llevar ese razonamiento al despojo de lo emocional, así, de la misma manera en que se ha fetichizado el objeto fabricado, se ha despojado al ser humano de su relación emocional con la naturaleza. El fetiche "fue desarrollado para, literalmente, demonizar el poder de los "extraños" objetos utilizados. Y surgió junto con el sujeto europeo, el que simultáneamente subyugaba y esclavizaba otros sujetos a la par que proclamaba su independencia de los objetos materiales" (Stallybrass, 2008, p. 3).

Stallybrass (2008, p. 3) establece que los comerciantes europeos le llamaban fetiches a las "cosas valiosas" que poseían otros para vaciarlos de todo simbolismo y apropiarse de estos. Desde el discurso hegemónico de la racionalidad, las clases dominantes despojaron a las personas del apego y de los elementos mágicos que se le atribuían a los objetos, así, el término de fetichización se convirtió en una forma de dominación para extraer los recursos y convertirlos en mercancía.

\footnotetext{
Pero esta constante repetición de "fetichismo" como categoría de abuso más que iluminar, reproduce el problema. Los comerciantes europeos, al menos después de la etapa temprana del comercio, no fetichizaban los objetos; por el contrario: se interesaban en los objetos en la medida en que podían transformarlos en mercaderías y cambiarlos con beneficios en el mercado. Como término del abuso económico, el concepto de fetiche definió a aquellos con los que los comerciantes europeos traficaron en África y en las Américas como gente que adoraba tanto bagatelas ("meros" fetiches) como cosas "valiosas" (i.e. oro y plata). Esto significó que podían ser "engañados”. (...) Lo que era demonizado en el concepto de fetiche fue la posibilidad de que la historia, la memoria y el deseo pudieran ser materializados en objetos tocados, amados, llevados en el cuerpo (Stallybrass, 2008, pp. 3-4)
}

La relación de los seres humanos con el entorno es como una relación con el objeto material. Sin embargo, conscientes de que tiene vida propia, la relación con este objeto es diferente a la relación con el objeto fabricado, conscientes de que no son seres sociales también es distinta de la relación con los seres humanos. Por tanto, la relación con la naturaleza es como con los objetos, pero objetos naturales. Es decir, que a pesar de que la naturaleza es un ser vivo, nos relacionamos con ella como si fuera un objeto viviente.

Entonces, a partir de lo desarrollado por Bellamy Foster (2013), Marx (2001) e Illouz (2007), se podría decir que, si el trabajador está alienado, la comprensión de la naturaleza se cosifica. Es decir, los recursos naturales se vuelven para él una cosa, tal cual una máquina o un objeto. En los medios precapitalistas imperaba la noción de preservar y devolver a la naturaleza lo que se había extraído de ella, al haber una relación emocional con el ecosistema, a éste se le concebía con vida propia y por ello las personas interactuaban con la naturaleza de manera metabólica. 
Así, cuando el trabajador está enajenado, la naturaleza se vuelve un objeto extraño y la vida genérica se convierte en un simple medio (Marx 2001, pp. 123-130). El capitalismo, al fracturar la relación emocional entre el ser humano y la naturaleza, rompe con la relación metabólica, pues ya la naturaleza no tiene vida propia, sino que se convierte en un medio para generar plusvalor y renta. Entonces, así como establece Illauz (2007) que el capitalismo separa las emociones de sí mismos porque mercantiliza las relaciones, también lo hace, inicialmente con la naturaleza.

\footnotetext{
En el concepto de alienación en Marx -que resultaba central para explicar la relación del trabajador con el proceso y el producto del trabajo- tenía fuertes vicios emocionales, como cuando Marx, en los Manuscritos económico filosóficos, analiza el trabajo alienado como una pérdida de realidad, en sus palabras, una pérdida en lo relativo al vínculo con el objeto. La modernidad y el capitalismo eran alienantes en el sentido de que creaban un tipo de entumecimiento emocional que separaba a las personas entre sí, de su comunidad y de su yo profundo (Illouz, 2007, p. 12).
}

Las formas de trabajo en las sociedades precapitalistas involucraban, per se, la relación entre ser humano y naturaleza. Actualmente, las formas de trabajo son con las máquinas, no se contempla la relación con la naturaleza en términos de producción y generación de capital. Por tanto, una de las fracturas metabólicas entre el ser humano y la naturaleza es el suprimir el Homo Sentimentalis de esa relación. Ya que trasciende las formas de producción y de trabajo pre o capitalistas, las trasciende en tanto que ya no es solo un organismo, sino que en las sociedades no capitalistas existe la noción de que la naturaleza tiene vida e interactúa con el ser humano, por tanto, sus acciones emocionales son mantener el ciclo natural y la relación metabólica.

Mientras que en las modalidades capitalistas se despropia al trabajador de su relación afectiva con la naturaleza para poder apropiarse de ella como un objeto, no solo le objetiva su vida genérica, sino que rompe con las dinámicas metabólicas de relacionarse con ella para pasar a dinámicas de explotación de la tierra, para su supervivencia, ya que esta última depende de las ganancias que se generen para el capitalista. Por tanto, al suprimir al Homos Sentimentalis también se suprime la actividad vital consciente.

Cuando Marx habla de la relación subjetiva con la naturaleza, no solamente se debe pensar en modalidades de producción precapitalistas, sino que se le puede atribuir características afectivas a esa relación, inclusive elementos de lo sagrado que permitían mantener un equilibrio no solo con el entorno sino también en términos de relaciones sociales. En este sentido, hay una vinculación material e inmaterial. Inmaterial porque los animales, los ríos, el bosque y la tierra están cargados de simbolismos que cobran vida en lo anecdótico, en el conocimiento, en las formas de cuidado y preservación del entorno. Sin embargo, el capitalismo se ha apropiado de las relaciones afectivas con el entorno natural para suprimirlas o bien para mercantilizarlas, pues, como explica Illouz (2009), existe una relación entre afectos, capitalismo y clase. En el capitalismo las emociones están reguladas, "tiene que ver con una forma secular de violencia dirigida y aplicada a producir expropiación de lo que sentimos” (Machado, 2012, p. 25)

Por ello, es necesario pensar el despojo del Homo Sentimentalis en términos de dinámicas de acumulación de capital. La relación emocional con la naturaleza se fetichiza, como fueron fetichizados los objetos valiosos. Con el capitalismo la naturaleza es materia prima para la creación de objetos fabricados, así que si la naturaleza adquiere el significado de objeto puede ser explotada al igual que ha sido explotado el ser humano. Cuando el subordinado logra mirar a la naturaleza como un objeto despojado de emociones es cuando logra explotar la naturaleza para el capitalista. Entonces, al despojar al trabajador de la relación afectiva con la naturaleza, se considera que se aliena en dos vías: por un lado, desde el trabajo enajenado y la explotación de la naturaleza. Por otro lado, como lo sugiere Illouz (2007 y 2009) y Stallybrass (2008) desde los afectos por las mercancías.

\section{CONCLUSIONES}

Entonces, de manera concluyente se afirma que hay relaciones entre el despojo del Homo Sentimentalis 
con la naturaleza, el trabajo enajenado y las dinámicas de acumulación de capital. Esta relación se resume en que con la propiedad privada el capitalista se apropia de la naturaleza, dispone de ella como un objeto natural, al igual que se apropia de la fuerza trabajo y de la mercancía. Por tanto, en las dinámicas de producción capitalistas el trabajador debe explotar la naturaleza para el capitalista, así que este lo despoja de su relación afectiva con ella, racionalizando las dinámicas de producción.

Con la transición a la modernidad capitalista, el ser humano comenzó a relacionarse con el entorno natural de maneras similares a como lo hacía con los objetos fabricados; por ello la naturaleza se vuelve un objeto natural. Tomando esto en cuenta, hay que leer lo subjetivo de las relaciones de producción también en términos de las relaciones afectivas con el entorno, no solo en las meras dinámicas productivas. Sino estaríamos anulando una forma de despojo que es central para comprender la relación entre ser humano, trabajo y entorno, presentes en las dinámicas de acumulación de capital. Además, lo emocional hay que leerlo más allá del romanticismo y el deseo en las relaciones con otras personas y el objeto fabricado, también hay afectos con el entorno natural que el capitalismo negó y despojó en aras de la explotación y la acumulación de capital.

El objeto fabricado y el objeto natural adquieren significaciones individuales y colectivas distintas, marcadas por las relaciones socioculturales y económicas. Los objetos adquieren valor para las personas en tanto sean mercancía, los objetos naturales pueden ser mercancía y a la vez materia prima. Así mismo, cuando es transformada, se comporta como objeto fabricado. Cuando son materia prima se les expropia de todo valor simbólico y subjetivo para explotarla y convertirla en valor de uso. Mientras que, cuando es mercancía y objeto fabricado adquiere significaciones. Así, el despojo de lo emocional por la naturaleza tuvo su génesis en dinámicas similares a las de la fetichización de los objetos valiosos.

Desde la ecología feminista se entiende que lo emocional se traslada a lo privado, mientras que lo público se objetiva y racionaliza. Esto como una formar de dominación sobre el subordinado. La racionalidad e instrumentalización del trabajo es una forma de enajenación y explotación, ya que se mercantiliza su trabajo y su relación con el entorno. La ruptura de la relación emocional del ser humano con la naturaleza se manifiesta como parte del proceso de acumulación de capital, donde subyacen las características de propiedad privada, trabajo enajenado, explotación del subordinado y de la naturaleza.

Una de las relaciones entre despojo del Homo Sentimentalis, el trabajo enajenado y la relación con la naturaleza es la ruptura metabólica. Por tanto, este concepto va más allá de las nociones ecológicas. Es una forma de dominación enmarcada en los procesos socioculturales de la modernidad regidas por la acumulación de capital y las lógicas de desposesión por racionalización de los procesos de trabajo. Entonces, la relación metabólica con la naturaleza es un fenómeno sociocultural que está atravesado por lo emocional y que ha sufrido transformaciones y rupturas con las lógicas capitalistas y los procesos de modernización. Si bien el capitalismo no despoja por completo la relación entre ser humano y naturaleza si se traslapan las relaciones subjetivas y objetivas acá expuestas, el despojo a fin de cuentas radica en la mercantilización del mundo natural, es decir, se objetiva y adquiere valor de uso en el mercado de capitales.

Con la alienación del ser humano y la objetivación de la vida genérica, el capitalista subsume al subordinado a dinámicas de trabajo precario y mecánico, este velará por sus condiciones laborales, por el sustento familiar, por la supervivencia y la reproducción de la vida. Mas no por la relación metabólica con la naturaleza, ya que su forma de sobrevivir en el sistema es la explotación de ella; generar plusvalor y renta para el capitalista. En las dinámicas de enajenación también se da un proceso de auto despojo de dichas emociones. El trabajador explota la naturaleza, no porque su esencia sea desalmada, sino porque debe convertirla en materia de trabajo, forma parte de la actividad productiva, la cual es externa a él, no le pertenece.

Las lógicas capitalistas transforman las relaciones afectivas con las demás personas, el espacio, los objetos y la naturaleza. Ya Marx (2001) mencionaba que con la propiedad privada y la explotación la naturaleza se objetiva; se vuelve extraña para el ser humano. Tomando esto en cuenta se considera que en las dinámicas de la modernidad el entorno natural está adentro y afuera de las relaciones sociales, la relación que tiene el ser humano con este forma parte de la sociedad como tal y de las interacciones, pero ni hay una relación recíproca ni se manifiestan las mismas afectividades que con otros seres humanos. La racio- 
nalidad hegemónica ha despojado al ser humano de los afectos por la naturaleza de tal manera que se relaciona con ella como si fuera un objeto del que se puede disponer para la producción, la explotación y la acumulación de capital.

Entonces, el despojo del Homo Sentimetalis se logra a partir de tres características esenciales del capitalismo: la propiedad privada, el trabajo enajenado y la fetichización de la naturaleza. Primero, el entorno natural al volverse privado el capitalista dispone de este, le pertenece. Forma parte de su materia prima para la producción, así que la privatiza y la cosifica tal cual un instrumento o una herramienta para que el subordinado explote ese recurso. Segundo, el subordinado en términos sencillos necesita trabajar para vivir, por tanto, debe someterse a las demandas del capitalista, este al controlar los medios de producción, controla las relaciones y los modos de vida. Tercero, la naturaleza se convierte en un objeto, con características de valor de uso y valor de cambio, se explota y se mercantiliza.

\section{REFERENCIAS}

Alimonda, H. (2011). La colonialidad de la naturaleza. Una aproximación a la ecología política latinoamericana. En H. Alimonda. La naturaleza colonizada. Ecología política y minería en América Latina. (pp. 21-59). CLACSO.

Ayala, M., Zapata, E. y Cortés, R. (2017). Extractivismo: expresión del sistema capitalista-colonial-patriarcal. Ecología Política, (54). 60-64. https://www.jstor.org/stable/44645637

Bellamy-Foster, J. (2014). Marx y la fractura en el metabolismo universal de la naturaleza. Herramienta web 15. http:// www.herramienta.com.ar/herramienta-web15/marx-y-la-fractura-en-el-metabolismo-universal-de-la-naturaleza

Berlant, L. y Golubov, N. (2012). Optimismo cruel. Debate Feminista, 45: 107-135.

Bravo, E. (2013). La crisis ambiental y los derechos de la naturaleza: una visión desde la ecología política. La Granja 17(1), 44-52. https://doi.org/10.17163//gr.n17.2013.04

Descola, P. (2012). Del totemismo como ontología. En H. Lavazza. Más allá de naturaleza y cultura (pp. 221-300). Amorrortu.

Durkheim, E. (1997). Las reglas del método sociológico y otros escritos sobre filosofía de las ciencias sociales. Fondo de cultura Económica.

Elmhirst, R. y Gonzákz, H. (2017). Ecologías políticas feministas: perspectivas situadas y abordajes emergentes. Ecología Política (54).50-57. https://www.jstor.org/stable/44645636

Escobar, A. (2011). Ecología política de la globalidad y la diferencia. En La naturaleza colonizada. En H. Alimonda. La naturaleza colonizada. Ecología política y minería en América Latina. CLACSO.

Federici, S. (2010). Calibán y la bruja. Mujeres, cuerpo y acumulación originaria. Traficantes de sueños.

Harvey, D. (2004). El “nuevo” imperialismo: acumulación por desposesión. CLACSO.

Horkheimer, M. y Adorno, T. (1998). Excursus I: Odiseo, o mito e ilustración en Dialéctica de la ilustración (pp. 97-129). En M, Horkheimer. Fragmentos filosóficos. Simancas Ediciones. SA.

Howell, S. (2001). ¿Naturaleza en la cultura o cultura en la naturaleza? Las ideas chewong sobre los humanos y otras especies. En P. Descola, y G. Pálsson, (eds). Naturaleza y sociedad: perspectivas antopológicas. (pp. 149-168). Siglo XXI

Illouz, E. (2007). Intimidades congeladas. Las emociones en el capitalismo. Katz Editores.

Illouz, E. (2009). El consumo de la utopía romántica: El amor y las contradicciones culturales del capitalismo. Katz Editores.

Ingold, T. (2011). Consideraciones de un antropólogo sobre la biología. En, L. Montenegro Martínez, (ed). Cultura y naturaleza: aproximaciones a propósito del bicentenario de la independencia de Colombia (pp. 99-134). Jardín Botánico de Bogotá José Celestino Mutis.

Lowy, M. (2003). Progreso destructivo: Marx, Engels y la ecología. En Harribey y Michael Lowy (ed.) Capital contra natura. PUF

Machado, H. (2012). Orden neocolonial, extractivismo y ecología política de las emociones. Revista Brasileira de Sociologia da Emocao, 12(34), 11-43. http://www.cchla.ufpb.br/rbse/Index.html

Machado, H. (2010). La naturaleza como objeto colonial. Una mirada desde la condición eco-bio-política del colonialismo contemporáneo. Boletín Onteaiken, (10), 36-47.

Marx, K. (2014). Capítulo V Proceso de trabajo y proceso de valoración. En K, Marx. El capital, Tomo I, sección tres. Siglo XXI.

Marx, K. (2001). Manuscritos económicos y filosóficos. Editorial MIA.

Santos, C. (2014). Naturalismos y acumulación por desposesión: paradojas del desarrollo sustentable. Horizontes an- 
tropológicos, 20(41), 331-356. https://doi.org/10.1590/S0104-71832014000100012

Schmidt, A. (2012). El concepto de naturaleza en Marx. Siglo XXI.

Stallybrass, P. (2008). El saco de Marx. Autêntica Editora.

Svampa, M. (2015). Feminismos del Sur y ecofeminismo. Revista Nueva sociedad, (256). 127-131. https://nuso.org/articulo/feminismos-del-sur-y-ecofeminismo/

Svampa, M. (2008). La disputa por el desarrollo: territorio, movimiento de carácter socio-ambiental y discursos dominantes: http://www.maristellasvampa.net/archivos/ensayo43.pdf

Weber, M. (2002). Economía y sociedad. Fondo de Cultura Económica.

\section{AUTORA}

Diana Gómez Calderón. Licenciada en Sociología por la Universidad de Costa Rica. Egresada de la Maestría de Investigación en Sociología de la FLACSO sede Ecuador. Investigadora en temas laborales, capitalismo y Modernidad.

\section{Conflicto de intereses}

La autora declara ningún conflicto de interés posible.

\section{Financiamiento}

El artículo se realiza en el marco de la Maestría de Investigación en Sociología de la FLACSO sede Ecuador, becaria.

Agradecimientos

$\mathrm{N} / \mathrm{A}$ 